\title{
Microdomains for Dopamine Volume Neurotransmission in Primate Prefrontal Cortex
}

\author{
Constantinos D. Paspalas and Patricia S. Goldman-Rakic ${ }^{\dagger}$
}

The explicit yet enigmatic involvement of dopamine in cortical physiology is in part volumetric (beyond the synapse), as is apparently the action of neuroleptics targeting dopamine receptors. The notion that nonsynaptic neuronal membranes would translate extracellular dopamine into receptor-specific spatiotemporal downstream signaling, similar to the chemical synapse, is intriguing. Here, we report that dopamine $\mathrm{D}_{5}$ (but not $\mathrm{D}_{1}$ or $\mathrm{D}_{2}$ ) receptors in the perisomatic plasma membrane of prefrontal cortical neurons form discrete and exclusively extrasynaptic microdomains with inositol 1,4,5-trisphosphate-gated calcium stores of subsurface cisterns and mitochondria. These findings introduce a novel dopaminoceptive substratum in the brain and a unique $\mathrm{D}_{5}$ receptor-specific signaling paradigm.

Key words: dopamine receptor; InsP3 receptor; subsurface cistern; electron microscopy; neuronal calcium; microdomain; prefrontal cortex; working memory

\section{Introduction}

In the primate prefrontal cortex (PFC), dopamine (DA) signaling is implicated in complex cognitive operations, the actions of drugs of abuse, and devastating neuropsychiatric disorders, including schizophrenia (Brozoski et al., 1979; Goldman-Rakic, 1987, 2002; Lidow et al., 1998; Carlsson et al., 2001; Weinberger et al., 2001). Yet many of these explicitly specific actions result from DA signals reaching via gradient diffusion receptors on proximal and remote nonsynaptic membranes (Goldman-Rakic et al., 1997; Pickel, 2000) [see reviews edited by Agnati et al. (2000) for a comprehensive account on volume neurotransmission]. Efficacy and cellular compartmentalization of extrasynaptic DA receptors (DARs) is therefore presumed to account for distinctive neuromodulatory and neuropharmacological patterns via specific signal transduction mechanisms assigned to individual receptor subtypes (Goldman-Rakic et al., 1997; Missale et al., 1998).

Three decades after volumetric signaling was first introduced as a potent mechanism of interneuronal communication (for review, see Dismukes, 1977; Beaudet and Descarries, 1978; Agnati et al., 1995b), our understanding of receptors and effector systems mediating volume neurotransmission remains mostly incomplete. This is primarily because these receptors, unlike their synaptic counterparts, do not seem to operate within discrete signaling modules in the brain. These views have recently been

Received Jan. 18, 2004; revised April 1, 2004; accepted April 29, 2004

This work was supported by National Institutes of Health Grant MH44866 (P.S.G.-R.). This study is dedicated to the memory of Patricia Shoer Goldman-Rakic. C.D.P. is indebted to R. Moratalla and Z. Khan for generously providing the $D_{5} R$ antibodies, K. Szigeti for technical assistance, and C. Bergson, B. Ehrlich, T. Koos, M. Yeckel, and P. Rakic for critical comments and discussion.

'Deceased July 31, 2003.

Correspondence should be addressed to Dr. Constantinos D. Paspalas, Yale University School of Medicine, Department of Neurobiology, Sterling Hall of Medicine B408, 333 Cedar Street, New Haven, CT 06510. E-mail: constantinos.paspalas@yale.edu.

DOI:10.1523/JNEUROSCI.0195-04.2004

Copyright $\odot 2004$ Society for Neuroscience $\quad$ 0270-6474/04/245292-09\$15.00/0 challenged by the evolving concept of the signaling microdomain. Elegant physiological and biochemical studies suggest the presence of microdomains that couple exogenous activation with a specific set of transduction molecules on intracellular membranes, thereby facilitating downstream signaling and encoding the stimulus spatiotemporal pattern and the signal transduction mechanisms of individual receptors (for review, see Berridge, 1998; Fagni et al., 2000; Delmas and Brown, 2002; Johenning and Ehrlich, 2002; Augustine et al., 2003). In effect, a signaling microdomain would operate as a signal amplification module to ensure fidelity of transmission and potentially to translate local events into global responses by engaging universal second messengers. Of key significance is the compartmentalization of the local cytosol that sequesters ionic and biochemical pools, exemplified by the dendritic spine, and the phosphoinositide system mobilizing calcium $\left(\mathrm{Ca}^{2+}\right)$ from intracellular stores via the 1,4,5trisphosphate receptor $\left(\operatorname{InsP}_{3} \mathrm{R}\right)$ (Berridge, 1993).

Given the importance of volume transmission mechanisms for DA physiology and neuropsychopharmacology (Zoli et al., 1999) and the potential of the signaling microdomain for maintaining input specificity and selectivity of regulation, we evaluated the plausibility of an evolving hypothesis that such modules may in fact exist in neurons to facilitate "diffuse" dopaminoception. We used high-resolution immunoelectron microscopy to study expression patterns of the $\mathrm{D}_{1}$-like DARs ( $\mathrm{D}_{1}$-LRs; i.e., $\mathrm{D}_{1}$ and $\mathrm{D}_{5}$ subtypes) and the $\mathrm{D}_{2}$ subtype, the prototypic receptor of the $\mathrm{D}_{2}$-like subfamily (for review, see Missale et al., 1998), in the pyramidal perisomatic region. This compartment, unlike dendritic spines, includes a massive single cytosolic volume and, in the PFC of primates, bears rare association with DAergic afferents (Smiley and Goldman-Rakic, 1993; Sesack et al. 1995). More importantly, the perisomatic plasma membrane is uniquely furnished with subsurface cisterns (SSCs) (see Fig. 1 for an overview), which would ultimately ensure cytosol compartmentalization and serve as scaffold for molecules mediating downstream effects. 
Table 1. Receptor antibodies utilized in single (s) and dual (d) immunoprocedures

\begin{tabular}{|c|c|c|c|c|}
\hline Antibody & Immunogen & Host & Dilution & Source \\
\hline Anti- $D_{1} R$ & $\begin{array}{l}\text { ( terminus (human) } \\
\text { aa } 349-446\end{array}$ & Clone 11- F11 S.E6 & $1: 800(s)$ & Sigma-RBI, St Louis, M0 \\
\hline Anti- $D_{2} R$ & $\begin{array}{l}\text { ¡3 loop (human) } \\
\text { aa 284-311 }\end{array}$ & Rabbit & $1: 500(s)$ & Chemicon, Temecula, CA \\
\hline Anti- $D_{5} R$ & $\begin{array}{l}\text { ( terminus (human) } \\
\text { aa } 428-438\end{array}$ & Rabbit & $\begin{array}{l}1: 1000(s) \\
1: 1200(d)\end{array}$ & Dr. Z. U. Khan, University of Malaga, Spain \\
\hline Anti- $D_{5} R$ & $\begin{array}{l}\text { ( terminus (mouse) } \\
\text { aa } 377-477\end{array}$ & Rabbit & $\begin{array}{l}1: 1500(s) \\
1: 2000(d)\end{array}$ & Dr. R. Moratalla, Institute Cajal, Spain \\
\hline Anti-InsP $P_{3} R$ & $\begin{array}{l}\text { ( terminus (human) } \\
\text { aa } 2492-2502\end{array}$ & Clone IPR0.1 & $1: 200(d)$ & Calbiochem, San Diego, CA \\
\hline Anti-InsP ${ }_{3} R$ & $\begin{array}{l}\text { ( terminus (human) } \\
\text { aa } 2492-2502\end{array}$ & Clone IPR0.1 & $1: 200$ (d) & Chemicon \\
\hline Anti-InsP ${ }_{3} R$ & $\begin{array}{l}\text { ( terminus (human) } \\
\text { aa } 2596-2608\end{array}$ & Rabbit & $1: 250(s)$ & Chemicon \\
\hline
\end{tabular}

The amino acid sequence of immunogen peptides can be viewed on National Center for Biotechnology Information Sequence Viewer (free access) at: http://www.ncbi.nlm.nih.gov/entrez/viewer.fcgi?db= protein\&val; search for 118228 (D $\mathrm{R}_{1}$-human), 71937 ( $\mathrm{D}_{2} \mathrm{R}$-human), 32049 ( $\mathrm{D}_{5} \mathrm{R}$-human), 29789042 ( $\mathrm{D}_{5} \mathrm{R}$-mouse), and 10835023 (Ins $\mathrm{P}_{3} \mathrm{R}$-human).

\section{Materials and Methods}

Histology and immunoreagents. Two adult rhesus monkeys (Macaca mulatta) from the Yale Department of Neurobiology primate colony were anesthetized with sodium pentobarbital (100 mg/kg, i.v.) and perfused transcardially with oxygenated artificial CSF, followed by $4 \%$ paraformaldehyde $/ 0.08 \%$ glutaraldehyde in phosphate buffer (PB; $100 \mathrm{~mm}$ ) and aldehyde-free PB. Experimental procedures were conducted in accordance with federal and institutional guidelines. The brains were blocked coronally, vibrosliced at $60 \mu \mathrm{m}$, cryoprotected, and stored frozen at $-80^{\circ} \mathrm{C}$. Prefrontal cortical sections were thawed in $\mathrm{PB}$ and preincubated for $45 \mathrm{~min}$ in 10\% normal goat serum (NGS; Vector Laboratories, Burlingame, CA) and 2\% bovine serum albumin (BSA; Vector Laboratories) in Tris-buffered saline (TBS; $50 \mathrm{mM}$ ) before being transferred to primary antibodies (Table 1). Nanogold- and biotin-SP-conjugated IgG fragments were purchased from Nanoprobes (Yaphank, NY) and Jackson Immunoresearch (West Grove, PA), respectively. Unlabeled bridging antibodies and peroxidase-antiperoxidase complexes were from Sternberger Monoclonals (Lutherville, MD).

Single gold-based $D_{1} R, D_{2} R, D_{5} R$ immunocytochemistry. Primary antibodies diluted in TBS plus 2\% NGS (i.e., N-TBS) were applied for $36 \mathrm{hr}$ at $4^{\circ} \mathrm{C}$. Sections were then incubated for $2 \mathrm{hr}$ in 1:500 species-specific biotinylated $\mathrm{F}\left(\mathrm{ab}^{\prime}\right)_{2}$ and for another 2 hr in 1:200 goat anti-biotin Fab' conjugated to $1.4 \mathrm{~nm}$ gold cluster. Immunocomplexes were fixed for 5 min in $1 \%$ buffered glutaraldehyde and, after a thorough wash in ultrapure water, nanogold was enhanced for $8 \mathrm{~min}$ with a silver autometallographic developer (HQ Silver; Nanoprobes).

Dual gold-based and peroxidase-gold-based $D_{5} R / I n s P_{3} R$ immunocytochemistry. Primary antibodies in N-TBS were simultaneously applied for $48 \mathrm{hr}$ at $4^{\circ} \mathrm{C}$. To visualize the $\mathrm{D}_{5} \mathrm{R}$, sections were preincubated for $30 \mathrm{~min}$ in N-TBS supplemented with $0.1 \%$ acetylated BSA (Aurion, Wageningen, The Netherlands), $0.1 \%$ fish skin gelatin and $0.07 \%$ Tween 20 (i.e., gold buffer), and transferred for $3 \mathrm{hr}$ in nanogold-conjugated goat antirabbit Fab' (1:200 in gold buffer). After wash in ultrapure water and 20 mM sodium citrate, nanogold was enhanced for $12 \mathrm{~min}$ on ice with a gold developer (GoldEnhance; Nanoprobes). Subsequently, nanogoldconjugated goat anti-mouse Fab' (1:200) was applied for $4 \mathrm{hr}$ to probe the InsP ${ }_{3} \mathrm{R}$ primary antibody. Sections were finally postfixed in glutaraldehyde and transferred for $4 \mathrm{~min}$ to the gold developer to enhance the Ins $\mathrm{P}_{3} \mathrm{R}$-bound nanogold but also to enhance further (i.e., $12+4 \mathrm{~min}$ in total) the $\mathrm{D}_{5} \mathrm{R}$ gold signal of the first series (two-step autometallography). This sequential enhancement produced distinct, nonoverlapping particle-size groups (see Methodological Considerations). Alternatively, $\mathrm{D}_{5} \mathrm{Rs}$ were labeled in the second series using species-specific bridging antibodies and peroxidase-antiperoxidase tertiary complexes (1:200 in $\mathrm{N}$-TBS for $2 \mathrm{hr}$ each). Peroxidase activity was visualized in $0.025 \%$ diaminobenzidine (DAB) in TBS with the addition of $0.007 \%$ hydrogen peroxide. In this case, $\mathrm{Ins}_{3} \mathrm{Rs}$ were labeled as detailed above, with gold enhancement ranging from 3 to $8 \mathrm{~min}$ at $22^{\circ} \mathrm{C}$.
Electron microscopy. Sections were postfixed in 1\% buffered osmium tetroxide (15 and $30 \mathrm{~min}$ for silver- and gold-enhanced material, respectively), treated with ethanolic uranyl acetate en block, and finally embedded in Durcupan epoxy resin (Fluka, Steinheim, Switzerland) and polymerized at $58^{\circ} \mathrm{C}$ for $48 \mathrm{hr}$ under vacuum. Layers II-IV and V-VI of the

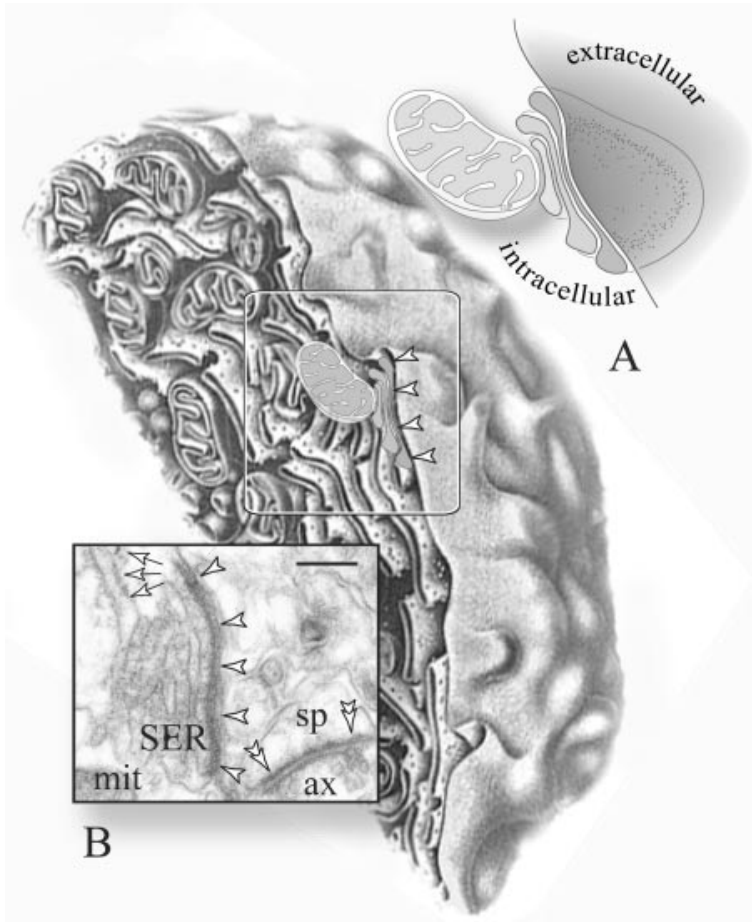

Figure 1. $A, B$, Schematic representation of the relative topography of the SSC ( $A$; arrowheads in frame and enlarged schema) and electron micrograph depicting oblique plane of section through the plasmalemma-SSC interface (B). As seen in B, SSCs typically consist of single or multiple flattened cisterns (electron opaque zone subjacent to the membrane; arrowheads), confluent through anastomoses with smooth reticular endomembranes (SER) and continuous with the rough endoplasmic reticulum (arrows). Therefore, an SSC derives from the reticular network of which is considered spatial and potentially functional modification. In the CNS and peripheral nervous system, SSCS are neuron specific and localized exclusively in perikarya and the most proximal portions of their processes (Rosenbluth, 1962; Henkart et al., 1976; Peters et al., 1991). Likewise, SSCs occur in perikarya and large-caliber proximal dendrites of cortical neurons (Rosenbluth, 1962; Buschmann, 1979; for review, see Peters et al., 1991) and are unique to the axon initial segment of principal cells (Palay et al., 1968; Benedeczky et al., 1994). Double arrowheads in B point to an axo-spinous synapse (ax-sp) next to the SSC. mit, Mitochondrion. Scale bar, $100 \mathrm{~nm}$. 
dorsolateral PFC (Walker's area 46) were sampled for thin sectioning and ultrastructural analysis under a JEM-1010 (Jeol, Tokyo, Japan) transmission electron microscope operated at $80 \mathrm{KV}$, with or without lead counterstaining.

Distinction between pyramidal and nonpyramidal neurons at the level of the perisomatic region was made on the basis of the established ultrastructural criteria for neuron-class identification in the neocortex, including the unique synaptology of each class (i.e., symmetric axosomatic and proximal axo-dendritic synapses for pyramids versus both symmetric and asymmetric synapses for interneurons) (Colonnier, 1981; Peters and Kara, 1985a,b).

Antibodies. The full characterization of the affinity-purified DAR antibodies has been detailed previously (Boundy et al., 1993; Levey et al., 1993; Khan et al., 2000; Centonze et al., 2003). The immunogen peptide for each subtype-specific antibody (Table 1) shows no sequence homology with other identified DARs. The $\mathrm{D}_{5} \mathrm{R}$ antibody (aa 377-477) has been characterized also in $D_{1} R$ null $(-/-)$ mice and shown not to cross-react with the homologous $\mathrm{D}_{1} \mathrm{R}$ subtype (Centonze et al., 2003). Various groups have provided additional characterization and applied these antibodies for the study of DARs in rodents, cats, humans, and nonhuman primates with various fixation protocols (Smiley et al., 1994; Bergson et al., 1995b; Yung et al., 1995; Rivera et al., 2002; Wang and Pickel, 2002). Both $\mathrm{D}_{5} \mathrm{R}$ antibodies labeled selectively plasmalemma/SSC complexes and revealed in the neuropil (data not shown) an expression pattern complementary to that of the $\mathrm{D}_{1} \mathrm{R}$, as described with antibodies raised against the 375-477 residue of the human $D_{5} R$ protein (Bergson et al., 1995b). The affinity-purified $\mathrm{InsP}_{3} \mathrm{R}$ monoclonal antibodies (Bourguignon et al., 1993, 1994) yielded indistinguishable labeling patterns in both the neuropil and the perisomatic region, targeting selectively the cytoplasmic face of reticular endomembranes as predicted from the transmembrane topology of the immunogen peptide (i.e., cytoplasmic $\mathrm{C}$ terminus sequence of the InsP $_{3} \mathrm{R}$ ) (see Fig. $5 A-D$ ). To confirm the specificity of immunolabeling for the $\operatorname{Ins}_{3} \mathrm{R}$, we used an affinitypurified polyclonal $\mathrm{Ins}_{3} \mathrm{R}$ antibody raised against a different amino acid sequence (aa 2596-2608 vs 2492-2502) (Table 1) of the human $\operatorname{InsP}_{3} \mathrm{R}$ C-terminal domain (Bourguignon et al., 1994; Wang et al., 2004). Nanogold immunocytochemistry with thisantibody revealed strong but sporadic $\mathrm{Ins}_{3} \mathrm{R}$ expression in dendritic spine apparata (supplemental Fig. $1 A$, available at www.jneurosci.org; compare with Fig. $5 A$ ) and prominentimmunolabeling of reticular endomembranes (supplemental Fig. $1 B-D$, available at www.jneurosci.org), which is consistent with the labeling patterns of the monoclonal Ins $\mathrm{P}_{3} \mathrm{R}$ antibodies (Fig. $5 B-D$ ) (see Results) and previous descriptions (Sharp et al., 1993). For all immunoprocedures, we monitored specificity and selectivity with a series of omission-substitution controls, including reversal of the dual labeling sequence (see Fig. $6 \mathrm{C}$ ) and prolonged gold enhancement $\left(10 \mathrm{~min}\right.$ at $22^{\circ} \mathrm{C}$ or 16 min on ice) after omitting the nanogold conjugates.

Methodological considerations. The single anddual gold-based immunoprocedures yielded distinctive particulate signals. The DAR single immunolabeling produced particle aggregates (Figs. $2 D-G, 3 A-E$ ) by introducing to the immunocomplex the long form SP-biotinylated antibody and multiple nanogold-tertiary antibodies. In dual immunolabeling, in contrast, a two-layer procedure with a stoichiometry close to 1 (i.e., 1 nanogold/immunocomplex) resulted in single immunoparticles (Fig. $4 A-D$, compare with Fig. $2 E-G$ ). In effect, the multiparticle approach combined with the more sensitive silver autometallography generally increased detection sensitivity, whereas the single-particle procedure provided higher spatial resolution because of the smaller immunocomplex and particle size. Finally, note the use of Tween 20 permeabilization in single-particle immunoprocedures for increasing the penetration of immunoprobes and facilitating labeling between tightly apposed membranes (Fig. 4A-C).

The peroxidase-gold methodology produced readily distinguishable immunocytochemical signals (amorphous precipitates vs particulate gold) (Fig. 6A, inset). However, immunoperoxidase, which can be a valuable auxiliary marker for initially exploring and confirming patterns of receptor expression, performs poorly when spatial resolution is required at the subcellular level (Novikoff, 1980). Therefore, only immunolabeling with gold probes was used for quantification throughout the study.

The sequential enhancement of nanogold with autometallography is based on the descriptions of Bienz and Egger (1998) for colloidal gold and was developed in our laboratory for receptor colocalization and independently reported by another group for cytoskeletal and vesicular 


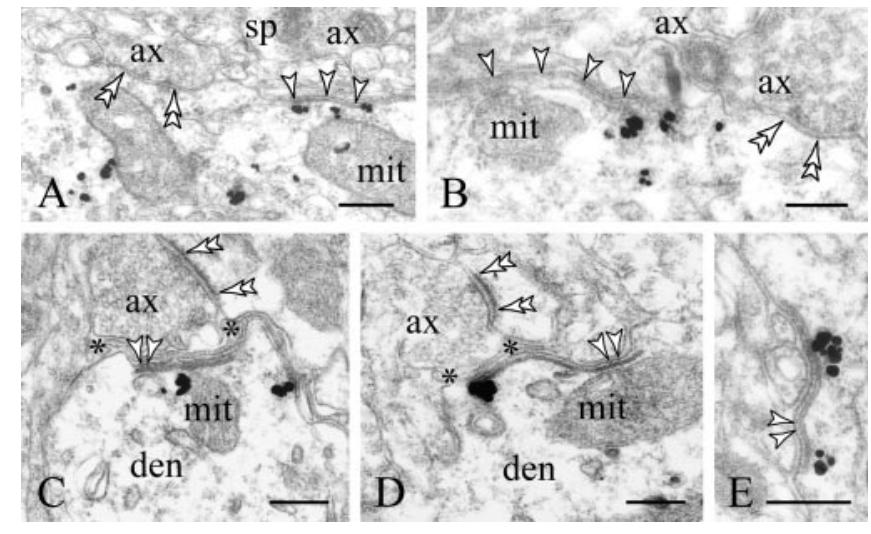

Figure 3. $D_{5} R$ expression in the perisomatic region. All panels depict nonpermeabilized material, hence the lack of immunolabeling in the plasmalemma-SSC interface (compare with Fig. 4). $A-E$, In perikarya $(A, B, E)$ and primary dendrites (den; $C, D), D_{5}$ Rs are selectively clustered subjacent to plasmalemma-SSC complexes ( $A, B$, arrowheads) or disposed on flanking membranes. Uncomplexed and synaptic ( $A, B$, double arrowheads) membranes are devoid of immunoreactivity. Sections shown in ( and $D$ belong to a series and are $280 \mathrm{~nm}$ apart. Notice how the mitochondrion (mit) in ( appears in D directly apposed to the SSC. In both micrographs, glial leaflets (asterisks) separate the plasmalemma-SSC complex from an apposed varicosity (ax) forming an asymmetric axo-spinous synapse (double arrowheads). In $C-E$, arrowheads point to periodic cross-bridges in the plasmalemma-SSC interface of similar size and periodicity to the tetrameric protrusions described in Purkinje SER membranes with freeze-fracture/replication (Kanaseki et al., 1998). It has been suggested that these electron-dense protrusions, which also appear in plasmalemma-SSC complexes of hippocampal pyramids (Benedeczky et al., 1994), may correspond to the fourfold symmetry of the tetrameric $\operatorname{Ins}_{3} R$ (Kanaseki et al., 1998; Jiang et al., 2002). Scale bars: $A, 300 \mathrm{~nm} ; B-E, 200 \mathrm{~nm}$.

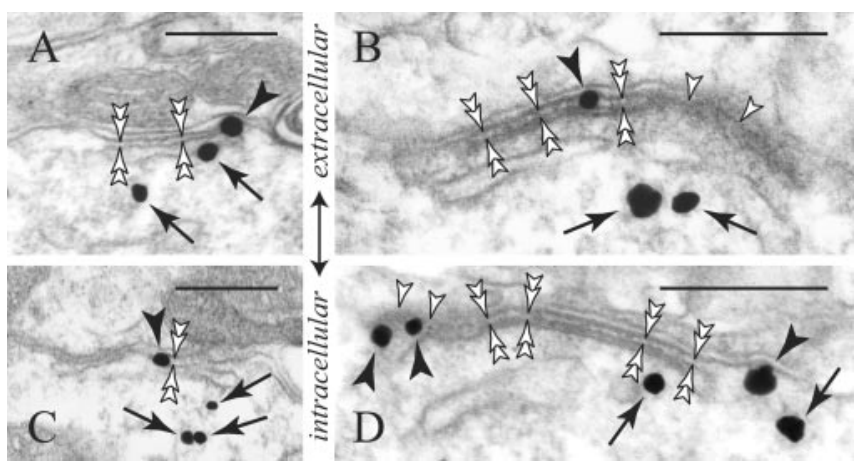

Figure 4. $\quad D_{5} R$ immunoreactivity visualized with single particles after membrane permeabilization. $A-D$, Arrows point to the receptor cytoplasmic pool, and arrowheads point to the plasmalemmal component on membranes overlying ( $A--C)$ or flanking $(D)$ SSCS. Notice how this architecture confines a $10-15 \mathrm{~nm}$ wide cytosolic microcompartment (double arrowheads) between the plasma membrane and the cisternal outer limiting membrane. White arrowheads point to an oblique section of the plasmalemma (and the SSC); the cytosolic microcompartment is not visible. Scale bars, $200 \mathrm{~nm}$.

proteins (Yi et al., 2001). To determine the optimal conditions for this experimental system, gold conjugates were sequentially introduced and gold enhanced, either being linked to antigens (supplemental Fig. $2 C-G$, available at www.jneurosci.org) or fixed directly on tissues with glutaraldehyde (supplemental Fig. $2 A, B$, available at www.jneurosci.org).

\section{Results}

This study pertains to the neuronal perisomatic region (i.e., perikaryon, axon initial segment, and proximal primary dendrites) known to include reticular specializations in the form of SSCs (see Fig. 1 for an overview). The smallest dendrite containing an SSC in our material had a diameter (minor axis) of $1.2 \mu \mathrm{m}$ and displayed rough endoplasmic reticular profiles (data not
Table 2. Extracellular milieu of the $D_{5} R$ microdomain

\begin{tabular}{|c|c|c|c|c|c|c|}
\hline Glut-like varicosities $^{a}$ & $\begin{array}{l}\text { Non-glut-like } \\
\text { varicosities }^{a}\end{array}$ & Dendrites & $\begin{array}{l}\text { Intervaricose } \\
\text { axon } \\
\text { segments }\end{array}$ & Gliab $^{b}$ & ND & Total \\
\hline $53-17$ & $22-8$ & $34-11$ & $17-4$ & $8-3$ & $11-3$ & $145-46$ \\
\hline
\end{tabular}

Paired values represent the number of $D_{5} R$ microdomains found in juxtaposition with individual cellular profiles in single and serial sections, respectively. Classification is based on form, size, organelle content, synaptology, and continuity with an identifiable structure [see Peters et al. (1991) for criteria]. Glut, Glutamatergic; ND, nonidentified cellular profiles.

${ }^{a} \mathrm{Glia}$ not including intervening processes separating axons.

${ }^{b}$ Direct apposition or apposition with intervening glial processes.

shown), which would accordingly correspond to a primary shaft, and generally SSCs were present in more proximal primary branches $(>1.6 \mu \mathrm{m})$ continuous with the perikaryon. The SSCs were almost exclusively localized in the perisomatic region of pyramidal cells, whereas they occurred rarely in perikarya and were virtually absent from the proximal processes of interneurons (see Materials and Methods for identification criteria). These rarely occurring SSCs in nonpyramidal neurons were never seen in association with DARs [see Khan et al. (2001) for $D_{2} R$, Muly et al. (1998) for $D_{1} R$ ]. In addition, both the $D_{5} R$ protein and $\mathrm{D}_{5} \mathrm{R}$ mRNA are localized predominantly in pyramidal neurons (Bergson et al., 1995a; Ariano et al., 1997; Ciliax et al., 2000). Therefore, in the following sections, we describe the subcellular expression patterns of DAR subtypes in the pyramidal perisomatic region.

The $D_{1}$ Rs comprised a highly immunoreactive cytoplasmic pool in specific association with the Golgi apparatus in perikarya and dendrites (Fig. 2A). Plasmalemmal expression, predominant in dendritic spines of the neuropil (Smiley et al., 1994), was not identified in the perisomatic region. In contrast, $\mathrm{D}_{2}$ Rs were not generally localized in the perisomatic region, with the exception of certain pyramids expressing weak immunoreactivity in rough endoplasmic reticular (RER) membranes, the Golgi, and in association with endosomes (Fig. $2 \mathrm{~B}$ ), consistent with the rare presence of $\mathrm{D}_{2}$ Rs in PFC efferents (Wang and Pickel, 2002). In these cells, nonsynaptic $\mathrm{D}_{2}$ Rs were additionally distributed on "uncomplexed" portions of the plasmalemma (i.e., lacking juxtaposed endomembranes; see below) (Fig. 2C). Overall, the perisomatic region expressed high levels of $\mathrm{D}_{5} \mathrm{R}$ immunoreactivity, with the exception of the axon initial segment. Indeed, labeling was rarely seen beyond the axon hillock (data not shown). The $\mathrm{D}_{5} \mathrm{R}$ immunoparticles labeled RER profiles deeper in the cytoplasm and formed distinct clusters below the cell surface (Fig. $2 D-G$ ) often in association with clathrin-coated vesicles (Fig. $2 D$ ). More importantly, the specific clustering of $D_{5}$ Rs subjacent to the plasma membrane invariably predicted the presence of a juxtaposed SSC (Figs. 2D-G, 3, 4). In addition to the cytoplasmic pool, we observed and examined in detail a plasmalemmal $D_{5} R$ component.

For the three-layer immunoprocedures, membrane-bound immunoparticles were defined as within $25 \mathrm{~nm}$ from the inner aspect of the plasmalemma. Proximity criteria were based on the size of the immunocomplex used for probing the intracellularly protruding $\mathrm{C}$ terminus of the receptor protein; equivalent to one IgG and two Fab' fragments, including the long-form biotin conjugate (see Materials and Methods). In two-layer immunoprocedures, $\mathrm{D}_{5} \mathrm{R}$ particles that appeared on the cytoplasmic face of the plasma membrane were considered plasmalemmal. We identified 618 membrane-bound immunoparticles in 26 perisomatic profiles of individual pyramids midsectioned through the apical dendrite (final magnification, $60,000 \times$ ). Ninety-three percent (577 particles) were 
distributed on membranes that overlay or flanked a juxtaposed SSC, at a distance no more than $80 \mathrm{~nm}$ of its margins (Figs. $2 F, G$, $3 A, B, D, 4 A-D)$. Spatial specificity of $\mathrm{D}_{5} \mathrm{R}$ expression was also manifest among the plasmalemma-SSC complexes of a single neuron, and occasionally highly immunopositive and immunonegative complexes were merely $0.5 \mu \mathrm{m}$ apart (Fig. $2 D$ ). The latter appeared characteristically devoid of the subjacent $\mathrm{D}_{5} \mathrm{R}$ cytoplasmic cluster, which also suggests that this cluster could represent an exchanging $D_{5} R$ pool locally associated with an overlying plasmalemmaSSC complex.

To determine whether this spatially restricted expression of $\mathrm{D}_{5}$ Rs along the perisomatic membrane is in response to synaptic input or other specific cellular apposition, we examined $\mathrm{D}_{5} \mathrm{R}$ plasmalemma-SSC complexes (called $\mathrm{D}_{5} \mathrm{R}$ microdomains hereafter) in single and successive sections (Table 2). Although the more frequently encountered appositions involved axons often forming asymmetric synapses with profiles other than the perisomatic membrane (Fig. 3C,D) (Alonso-Nanclares et al., 2004), the $\mathrm{D}_{5} \mathrm{R}$ microdomain was never directly associated with the symmetric synapses that typically converge on the pyramidal perisomatic region (Beaulieu and Colonnier, 1985) (Figs. 2D, $3 A, B$ ). This is of particular interest because cisternal structures have indeed been shown to accompany symmetric synapses (GABAergic) on the axon initial segment of hippocampal pyramids (Benedeczky et al., 1994) (Fig. 5D). In two single cases, we identified microdomains in somato-somatic plasma membrane juxtapositions (Fig. $6 H$ ).

Given the central role of reticular endomembranes (and the SSC) in $\mathrm{Ca}^{2+}$ homeostasis (Park et al., 2000; Meldolesi, 2001) and the capacity of $\mathrm{D}_{1}$-LRs to mobilize $\mathrm{Ca}^{2+}$ stores (for review, see Missale et al., 1998), we next examined whether the $D_{5} R$ microdomain could be a potential physical substrate for the phosphoinositide system by also expressing Ins $\mathrm{P}_{3}$ Rs. In the neuropil (Fig. $5 A, B$ ), InsP ${ }_{3}$ Rs were sporadically expressed in dendritic spine apparata and in slender vesicular structures within dendrites and rarely axonal varicosities. In the perisomatic region, we detected $\mathrm{InsP}_{3} \mathrm{Rs}$ on reticular endomembranes and rarely on Golgi complexes (Fig. 5C,D) (for Golgi as a $\mathrm{Ca}^{2+}$ signaling apparatus, see Pinton et al., 1998). Coexpression of $\mathrm{D}_{5} \mathrm{Rs}$ and $\mathrm{Ins}_{3} \mathrm{Rs}$ in individual microdomains was confirmed with different dual immunoprocedures (i.e., gold-gold- and peroxidase-gold-based; see Materials and Methods). Despite the inherent limitations of immunoperoxidase (discussed in Materials and Methods), DAB immunocytochemistry for the $\mathrm{D}_{5} \mathrm{R}$ labeled intensely plasmalemma-SSC complexes and often the subjacent cytoplasm, whereas precipitation over uncomplexed membranes and the juxtaposed cellular profiles was minimal or absent (Fig. $6 A$, compare with the gold labeling pattern in $B-H)$. The $\operatorname{InsP}_{3} \mathrm{R}$ immunoparticles labeled the lateral vacuolar expansions as well as central portions of the SSC limiting membranes (Fig. 6A-H).

Next, we sought to quantify the extent of colocalization of $\mathrm{D}_{5} \mathrm{Rs}$ and $\mathrm{Ins}_{3} \mathrm{Rs}$ in the pyramidal perisomatic region. However, note that this is a semiquantitative approach, for several factors discussed in the following section may influence differentially the immunolocalization of individual antigens. Because the number of SSCs in individual perisomatic profiles varies depending on the length of visible plasma membrane, we examined perisomatic regions midsectioned through the nucleus and the apical primary dendrite. In $\mathrm{D}_{5} \mathrm{R}$-Ins $\mathrm{P}_{3} \mathrm{R}$-immunolabeled material, we identified a total of 210 plasmalemma-SSC complexes (referred to as complexes) in 24 perisomatic profiles $(8.8 \pm 2.7$ complexes/profile; mean \pm SD; range, $4-14$ ). The majority (158 complexes; $75 \%$ ) expressed Ins $\mathrm{P}_{3} \mathrm{R}$ immunoreactivity on SSCs as described in the previous section. $\mathrm{D}_{5} \mathrm{R}$ immunoreactivity was identified in 96 of the complexes $(4 \pm 1.7$ complexes/profile; mean $\pm \mathrm{SD}$; range, $1-9)$, equal to $46 \%$ of total complexes. With the exception of two perisomatic profiles containing exclusively $\mathrm{D}_{5} \mathrm{R}$ complexes, immunopositive and immunonegative complexes for the $\mathrm{D}_{5} \mathrm{R}$ generally coexisted in individual profiles (Fig. 2D). Eighty-one $(84 \%)$ of $\mathrm{D}_{5} \mathrm{R}$ complexes expressed $\mathrm{Ins}_{3} \mathrm{Rs}$ immunoreactivity on SSCs. The remaining were immunonegative (Fig. $6 H$ ) or more frequently displayed $\mathrm{Ins}_{3} \mathrm{Rs}$ in association with other endomembranes in the vicinity of the SSC.

Having established the association of $\mathrm{D}_{5} \mathrm{Rs}$ with the $\operatorname{Ins}_{3} \mathrm{R}$ expressing cisternal endomembranes, we finally investigated whether the $\mathrm{Ins}_{3}$-sensitive stores of the microdomain could be additionally linked to the mitochondria, an important cytoplasmic component of the intracellular $\mathrm{Ca}^{2+}$ network (Rizzuto et al., 1994, 1998; Babcock et al., 1997). In 21\% $(n=100)$ of singlesectioned and $32 \%(n=46)$ of serially sectioned $\mathrm{D}_{5} \mathrm{R}$ microdomains (Fig. 3, compare $C$ and $D$ ), a single mitochondrion was directly apposed to the SSC, separated by a sparsely bridged $12-20 \mathrm{~nm}$ electron-lucent zone (Fig. $7 A-C$ ). In favorably sectioned appositions (Fig. $7 C$ ), we observed $\mathrm{Ins}_{3} \mathrm{R}$ immunoparticles within the minute cleft separating the cisternal from the mitochondrial outer membrane, apparently labeling the cisternal face because mitochondria are not known nor were they observed here to express $\mathrm{InsP}_{3} \mathrm{Rs}$.

\section{Discussion}

Although the perisomatic occurrence of the SSC has been documented in central and peripheral neurons (see Fig. 1 for review) and corroborated here for the macaque PFC, there is no compelling evidence until now, with respect to SSCs and neuronal classification. The original descriptions either do not distinguish between pyramidal and nonpyramidal neurons (Rosenbluth, 

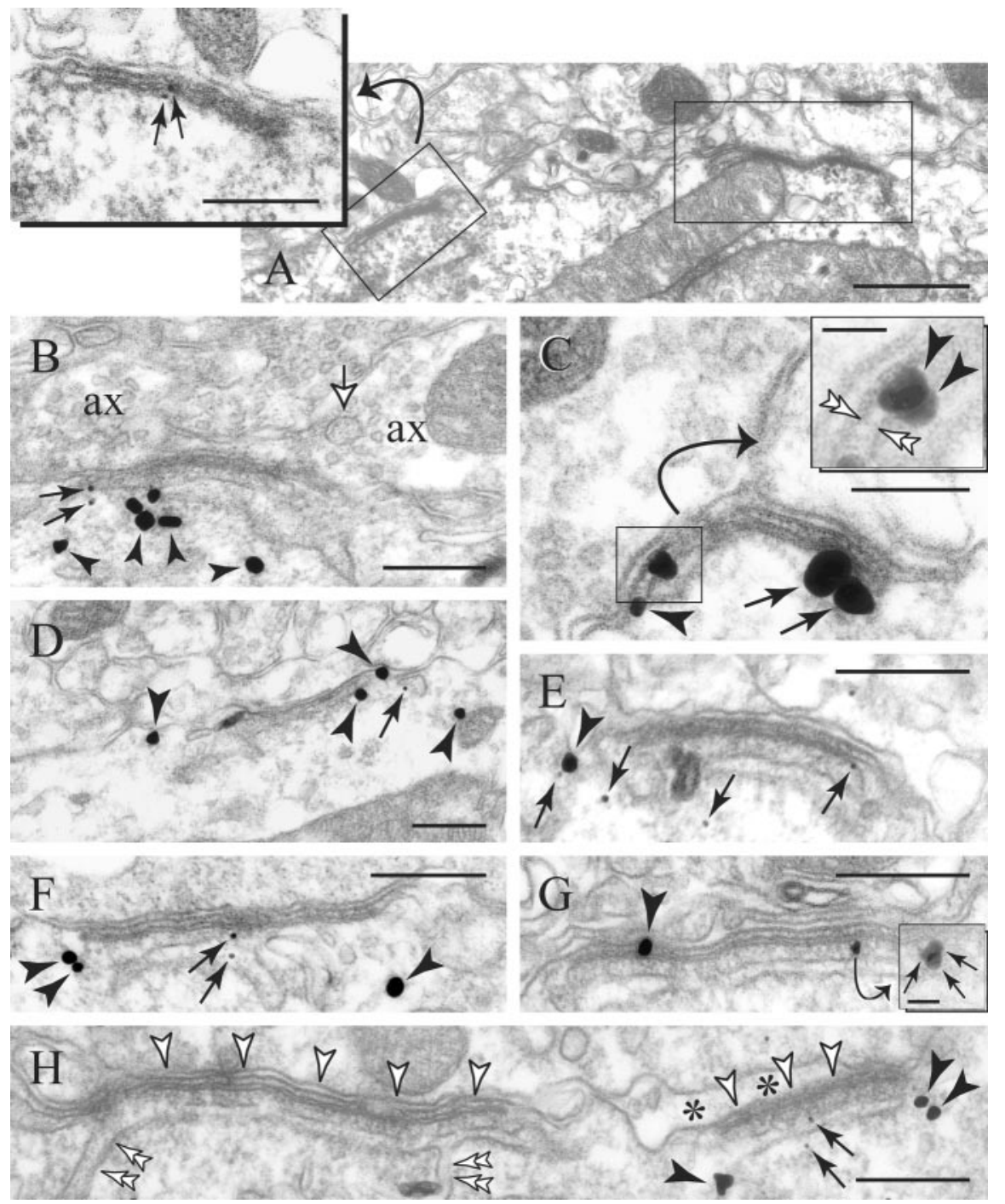

Figure 6. Coexpression of $\mathrm{D}_{5} \mathrm{Rs}$ and $\ln \mathrm{P}_{3} \mathrm{Rs}$ in microdomains. In $A, \mathrm{D}_{5} \mathrm{Rs}$ were visualized with immunoperoxidase precipitates. Despite the diffuse nature of the immunomarker, two plasmalemma-SSC complexes (framed) and the subjacent cytoplasm demonstrate increased labeling density compared with uncomplexed membranes or neighboring cellular profiles. Ins $\mathrm{P}_{3} \mathrm{Rs}_{\mathrm{s}}$ were simultaneously visualized with nanogold at high magnification (inset, arrows). To avoid artifactual contrasting of membranes, this material was processed with minimal lead counterstaining. For illustration purposes, image contrast in $A$ and inset has been enhanced digitally (Photoshop 7.0; Adobe Systems, San Jose, CA). When detected with nanogold probes (arrowheads), D $D_{5}$ Rs were visualized between the plasmalemma and juxtaposed cisternal endomembranes $(C$, inset, $G$ ), and predominantly at the periphery of plasmalemma-SSC complexes $(D, E)$. The Ins $\mathrm{P}_{3} \mathrm{R}$-immunoreactive profiles (arrows) included the lateral vacuolar expansions of SSCS $(B--E)$ and their middle portion $\left(A, F, G\right.$, inset, $H$ ). Note in $C$ the reversal of the immunolabeling sequence for $D_{5} R$ (small particles; main panel and inset) and $\operatorname{Ins}_{3} \mathrm{R}$ (large particles); double arrowheads point to the plasmalemma-SSC interface. $H$ illustrates a rare case of somato-somatic membrane juxtaposition furnished with two SSCs (white arrowheads); one SSC is confluent with the reticular network (double arrowheads). Notice that the plasmalemma-SSC complex, which is immunoreactive for both $\mathrm{D}_{5} \mathrm{Rs}$ and InsP $_{3} \mathrm{Rs}$, also coincides spatially with the widening of the perineuronal space (asterisks), perhaps to allow access via extracellular diffusion. White arrow in $B$ points to a dense-cored vesicle within a DAergic-like axon (ax) deployed en passant. Scale bars: $A, 500 \mathrm{~nm} ; A$ inset, $B, D--G, 200 \mathrm{~nm} ; G$ inset, $20 \mathrm{~nm} ; C, 100 \mathrm{~nm} ; C$ inset, $25 \mathrm{~nm}$.

1962) or report SSCs primarily in pyramids (Buschmann, 1979). Here, we confirmed the predominant localization of SSCs in pyramidal cells as opposed to interneurons. Moreover, the rarely occurring SSCs in nonpyramidal perikarya were never associated with DARs.

Within pyramidal neurons (Fig. 2), the DAR subtypes formed cytoplasmic pools $\left(D_{1} R, D_{2} R\right.$, and $\left.D_{5} R\right)$ and a membrane-bound component $\left(\mathrm{D}_{2} \mathrm{R}\right.$ and $\left.\mathrm{D}_{5} \mathrm{R}\right)$. The latter would represent the "functional" component of the perisomatic region, because active receptors signal from the plasma membrane and only these recep- tors would be available to extracellular DA. Another possibility to consider is that DARs could be additionally localized within postsynaptic densities of DAergic synapses preventing immunodetection with the preembedding method, as repeatedly demonstrated by Somogyi's group for ionotropic glutamate receptors [see Baude et al. (1995) for discussion on pre-embedding vs postembedding approaches]. Even for these receptors, however, one would expect the pre-embedding method to occasionally visualize relatively "unmasked" antigens, especially at the edges of the synapse (Baude et al., 1995), which was never observed here. Although it seems unlikely, considering the rare occurrence of perisomatic DAergic input (Goldman-Rakic et al., 1997), we cannot exclude this possibility. Likewise, we cannot preclude a biased immunodetection because of physical barriers (i.e., the tightly apposed plasmalemma and cisternal membranes) or other factors that may interfere with the dual immunolabeling, such as loss of gold signal of the first labeling series, reduced antigenicity in the second series, nonuniform preservation of antigenicity for $\mathrm{D}_{5} \mathrm{Rs}$ and $\mathrm{Ins}_{3} \mathrm{Rs}$ after fixation or simply different potencies of the individual antibodies. Therefore, one should bear in mind these inherent limitations when interpreting immunocytochemical findings.

We have established that $D_{5}$ Rs exhibit strict spatial specificity along the pyramidal perisomatic plasmalemma and form discrete and exclusively extrasynaptic microdomains. Moreover, this expression pattern appears to be unique to the $\mathrm{D}_{5} \mathrm{R}$, as manifested not only between subtypes of distinct DAR subfamilies ( $\mathrm{D}_{5} \mathrm{Rs}$ but not $\mathrm{D}_{2} \mathrm{Rs}$ ) but also between the structurally and pharmacologically homologous subtypes of the $D_{1}$-LR subfamily $\left(D_{5}\right.$ Rs but not $\left.D_{1} R s\right)$. To the best of our knowledge, the $D_{5} R$ microdomain is the first evidence for the existence of intricately structured neurotransmission modules in the brain exhibiting spatial-, receptor-, and cellclass/compartment specificity beyond the chemical synapse.

Evidently, such modules would never meet the exquisite "one-to-one" spatiotemporal requirement of the synapse. Therefore, they should not be viewed as an alternative to "wired" communication to compensate for the rare occurrence of perisomatic DA synapses but rather as a synergistic mechanism for the modulation of cellular assemblies (for review, see Agnati et al., 2000). Consistent with these views, the dopaminoceptive microdomain is strategically positioned to influence the neuronal excitability centrally by influencing directly the signal relay compartment of the cortical principal cell, as opposed to DAergic modulation of individual synapses on distal dendrites mediated primarily via the $D_{1} R$ (for review, see Goldman-Rakic et al., 


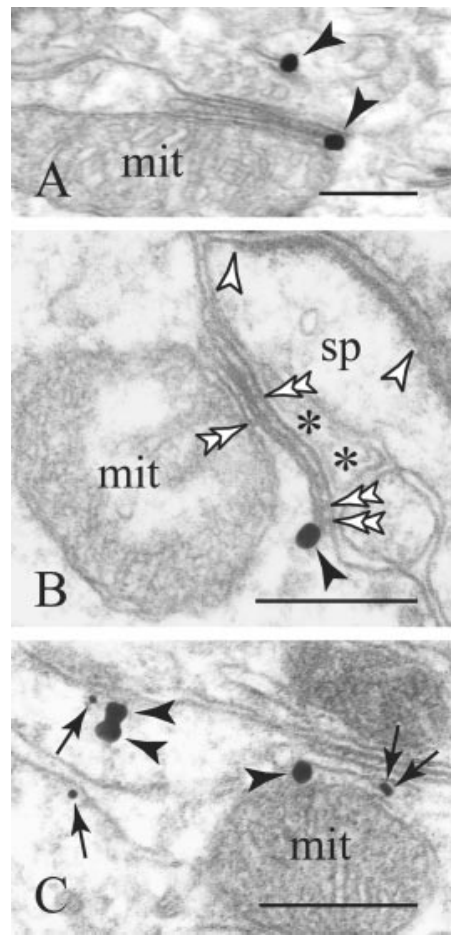

Figure 7. The $D_{5}$ R microdomains establish intimate associations with mitochondria (mit). $A$, $B, D_{5} R s$ (black arrowheads) are localized at the edges of the microdomain and on a neuropil profile $(A)$. A dendritic spine (sp) receiving an asymmetric synapse (between arrowheads in $B$ ) is apposed to the microdomain with intervening glial processes (asterisks); double arrowheads point to cross-bridges (Fig. 3 legend) in the plasmalemma-SSC and SSC-mitochondrion interface. ( depicts Ins $P_{3} R$ expression (two attached immunoparticles; arrows) within the minute cleft separating the cisternal from the outer mitochondrial membrane. Scale bars, $200 \mathrm{~nm}$.

2000). The selective expression of the high-affinity $D_{5} R$ (its affinity for DA is an order of magnitude higher than that of the $D_{1} R$ ) (Sunahara et al., 1991) will then favor perisomatic dopaminoception at relatively lower transmitter levels and potentially longrange volumetric signaling. Inevitably, the dopaminoceptive microdomain should be regarded as a potent substratum for $D_{1}$-LR pharmacological manipulation. It is noteworthy that chronic treatment with typical and atypical antipsychotics downregulates $\mathrm{D}_{5} \mathrm{R}$ mRNA in the PFC (Lidow et al., 1997), although it is not currently known whether this involves neuropilar or perisomatic $\mathrm{D}_{5}$ Rs.

The question naturally arises as to whether the $\mathrm{D}_{5}$ Rs could be organized in discrete microdomains independently of extrinsic signals (i.e., in response to the intracellular milieu) or, conversely, whether extrinsic signals may trigger clustering of the $D_{5} R$ and juxtaposition of cisternal membranes. Apparently, the clustered $\mathrm{D}_{5} \mathrm{R}$ expression is not in response to synapses (either DAergic or heterosynapses), and local extrasynaptic release of DA across the microdomain might seem unlikely considering the frequent juxtaposition of non-DAergic profiles (i.e., glutamatergic-like axons, dendrites, glia) (Table 2) (however, see the DAergic-like en passant axon in Fig. 6B). In fact, analyses of the DAergic innervation of the frontal cortex have confirmed the rare association of DA axons with the perisomatic region (Smiley and GoldmanRakic, 1993; Sesack et al. 1995; for review, see Goldman-Rakic et al., 1997). Nonetheless, this evidence does not necessarily imply that the perisomatic membrane is uniformly exposed to "circulating” DA. Glial barriers or heterogeneous distribution of DA transporters within individual axons (Lewis et al., 2001) could favor diffusion anisotropies (Barbour and Häusser, 1997; Gonon et al., 2000; Syková, 2001), which may ultimately result in spatially restricted elevations of DA levels ("hot spots") along the perisomatic membrane. These DAergic axons could be located in the relative vicinity of a microdomain or even more remotely within the parenchyma. Whether the nonuniformity of the plasmalemma with regard to extracellular DA may apply in vivo is only speculative. What is very interesting, however, is that both the SSC and mitochondria are most certainly dynamic structures, unlike their static images captured in electron microscopy. Early ultrastructural studies have demonstrated that SSCs are capable of plastic changes after axotomy and during development (Sumner, 1975; Buschmann, 1979), and recent evidence indicates that local $\mathrm{Ca}^{2+}$ dynamics may affect physical coupling between the smooth endoplasmic reticulum and mitochondria (Wang et al., 2000). Finally, we should consider the possibility of a dynamic trafficking between the plasmalemmal component and the cytoplasmic pool of the $\mathrm{D}_{5} \mathrm{R}$, as might indicate its selective clustering bellow the microdomain, often in association with clathrincoated vesicles (Fig. $2 D-G$ ). Compared with the $\mathrm{D}_{1} \mathrm{R}$, which undergoes dynamin-dependent endocytosis involving clathrincoated pits (Bloch et al., 1999; Vickery and Zastrow, 1999), little is known about the $\mathrm{D}_{5} \mathrm{R}$ regarding its handling after agonist stimulation. Although it appears to undergo agonist-induced internalization, similar to the $D_{1} R$, recent evidence suggests that after endocytosis the $\mathrm{D}_{5} \mathrm{R}$ is shorted for degradation in the lysosomes (Heydorn et al., 2004).

Although more studies, both anatomical and physiological, would be needed to elucidate these key issues, it is obvious that ligands (endogenous DA and pharmacological analogs) would reach the $\mathrm{D}_{5} \mathrm{R}$ microdomain, as well as other dopaminoceptive membranes, via volumetric diffusion (Zoli et al., 1999; Pickel, 2000). Even unoccupied $D_{5}$ Rs may retain substantial capacity for activating adenylyl cyclase by behaving as constitutively active receptors (Tiberi and Caron, 1994). Yet, unlike any other brain dopaminoceptive membranes, the $\mathrm{D}_{5} \mathrm{R}$ microdomain presents a unique cellular feature: the distinctive alignment of the $\mathrm{D}_{5} \mathrm{R}$ expressing membranes with the $\mathrm{InsP}_{3} \mathrm{R}$-furnished SSC and the mitochondrion, implying their involvement in similarly restricted intracellular signaling mechanisms to maintain input specificity and selectivity of regulation. It has been suggested, for example, that $\mathrm{InsP}_{3} \mathrm{Rs}$ expressed in the reticulum-mitochondrion interface, as shown here, would generate the essential $\mathrm{Ca}^{2+}$ hot spots for the low-affinity, high-capacity mitochondrial $\mathrm{Ca}^{2+}$ uniporter to operate, leading to sharp rise of matrix $\mathrm{Ca}^{2+}$ levels in response to $\mathrm{InsP}_{3}$ (Rizzuto et al., 1994, 1998). In essence, the $\mathrm{D}_{5} \mathrm{R}$ microdomain constitutes the equivalent of a nonprojecting "somatic spine" by sequestering the cytosol and by supplying the reticular scaffold, reminiscent of the spine apparatus, for specific macromolecular arrays, including the $\operatorname{Ins}_{3} \mathrm{R}$, to assemble and function (Berridge, 1998; Blackstone and Sheng, 1999; Delmas et al., 2002; Augustine et al., 2003).

Previous studies in behaving primates have established that the $D_{1}$-LRs are critically involved in working memory operations (Sawaguchi and Goldman-Rakic, 1994; Williams and GoldmanRakic, 1995; Castner et al., 2000), even though the lack of specific ligands for $\mathrm{D}_{1} \mathrm{R}$ and $\mathrm{D}_{5} \mathrm{R}$ subtypes has hitherto precluded consideration of their potentially distinct roles within the cortical microcircuitry (Gao and Goldman-Rakic, 2003). Moreover, their signal transduction mechanisms (for review, see Missale et al., 1998) have most commonly been linked to activation of adenylyl cyclase. In addition to the cAMP pathway, however, $\mathrm{D}_{1}$-LR activation increases the formation of inositol phosphates in the brain (Mahan et al., 1990; Undie and Friedman, 1990) and stimulates 
$\mathrm{Ca}^{2+}$ release from $\mathrm{InsP}_{3}$-sensitive stores in perikarya of dissociated cortical neurons (Lezcano and Bergson, 2002). It appears that the involvement of $\mathrm{D}_{1}$-LRs in the phosphatidylinositol turnover is independent of the cAMP pathway and is likely attributed to a subtype distinct from the prototypic $\mathrm{D}_{1} \mathrm{R}$ (Friedman et al., 1997). The discovery here of a specialized microdomain that facilitates selective physical coupling of the $\mathrm{D}_{5} \mathrm{R}$ and the phosphoinositide system introduces a unique signaling paradigm for the volumetric regulation of cortical functions by DA and identifies new targets (Agnati et al., 1995a) that could be involved in the numerous neuropsychiatric disorders affecting the brain DAergic system. This link can be particularly tempting in light of the recently discovered $\mathrm{Ca}^{2+}$-binding, DAR-interacting proteins and the proposed involvement of $\mathrm{Ca}^{2+}$ in the pathophysiology of schizophrenia (Bergson et al., 2003; Lidow, 2003).

\section{References}

Agnati LF, Bjelke B, Fuxe K (1995a) Volume versus wiring transmission in the brain: a new theoretical frame for neuropsychopharmacology. Med Res Rev 15:33-45.

Agnati LF, Zoli M, Strömberg I, Fuxe K (1995b) Intercellular communication in the brain: wiring versus volume transmission. Neuroscience 69:711-726.

Agnati LF, Fuxe K, Nicholson C, SykováE (2000) Progress in brain research, Vol 125. Volume transmission revisited. Amsterdam: Elsevier.

Alonso-Nanclares L, Minelli A, Melone M, Edwards RH, DeFelipe J, Conti F (2004) Perisomatic glutamatergic axon terminals: a novel feature of cortical synaptology revealed by vesicular glutamate transporter 1 immunostaining. Neuroscience 123:547-556.

Ariano MA, Wang J, Noblett KL, Larson ER, Sibley DR (1997) Cellular distribution of the rat $D_{1 B}$ receptor in central nervous system using antireceptor antisera. Brain Res 746:141-150.

Augustine GJ, Santamaria F, Tanaka K (2003) Local calcium signaling in neurons. Neuron 40:331-346.

Babcock DF, Herrington J, Goodwin PC, Park Y-B, Hille B (1997) Mitochondrial participation in the intracellular $\mathrm{Ca}^{2+}$ network. J Cell Biol 136:833-843.

Barbour B, Häusser M (1997) Intersynaptic diffusion of neurotransmitter. Trends Neurosci 20:377-384.

Baude A, Nusser Z, Molnár E, Mcllhinney RAJ, Somogyi P (1995) Highresolution immunogold localization of AMPA type glutamate receptor subunits at synaptic and non-synaptic sites in rat hippocampus. Neuroscience 69:1031-1055.

Beaudet A, Descarries L (1978) The monoamine innervation of rat cerebral cortex: synaptic and nonsynaptic axon terminals. Neuroscience 3:851-860.

Beaulieu C, Colonnier M (1985) A laminar analysis of the number of roundasymmetric and flat-symmetric synapses on spines, dendritic trunks, and cell bodies in area 17 of the cat. J Comp Neurol 231:180-189.

Benedeczky I, Molnár E, Somogyi P (1994) The cisternal organelle as a $\mathrm{Ca}^{2+}$-storing compartment associated with GABAergic synapses in the axon initial segment of hippocampal pyramidal neurons. Exp Brain Res 101:216-230.

Bergson C, Mrzljak L, Lidow MS, Goldman-Rakic PS (1995a) Characterization of subtype-specific antibodies to the human $\mathrm{D}_{5}$ dopamine receptor: studies in primate brain and transfected mammalian cells. Proc Natl Acad Sci USA 92:3468-3472.

Bergson C, Mrzljak L, Smiley JF, Pappy M, Levenson R, Goldman-Rakic PS (1995b) Regional, cellular, and subcellular variations in the distribution of D1 and D5 dopamine receptors in primate brain. J Neurosci 15:7821-7836.

Bergson C, Levenson R, Goldman-Rakic PS, Lidow MS (2003) Dopamine receptor-interacting proteins: the $\mathrm{Ca}^{2+}$ connection in dopamine signaling. Trends Pharmacol Sci 24:486-492.

Berridge MJ (1993) Inositol trisphosphate and cell signalling. Nature 361:315-325.

Berridge MJ (1998) Neuronal calcium signaling. Neuron 21:13-26.

Bienz K, Egger D (1998) Electron microscopic-silver enhancement for double labeling with antibodies raised in the same species. In: Methods in molecular biology-immunocytochemical protocols, Vol 80 (Pound JD, ed), pp 313-318. Totowa, NJ: Humana.
Blackstone C, Sheng M (1999) Protein targeting and calcium signaling microdomains in neuronal cells. Cell Calcium 26:181-192.

Bloch B, Dumartin B, Bernard V (1999) In vivo regulation of intraneuronal trafficking of $\mathrm{G}$ protein-coupled receptors for neurotransmitters. Trends Pharmacol Sci 20:315-319.

Boundy VA, Luedtke RR, Artymyshyn RP, Filtz TM, Molinoff PB (1993) Development of polyclonal anti-D2 dopamine receptor antibodies using sequence-specific peptides. Mol Pharmacol 43:666-676.

Bourguignon LYW, Jin H, Iida N, Brandt NR, Zhang SH (1993) The involvement of ankyrin in the regulation of inositol 1,4,5-trisphosphate receptor-mediated internal $\mathrm{Ca}^{2+}$ release from $\mathrm{Ca}^{2+}$ storage vesicles in mouse T-lymphoma cells. J Biol Chem 268:7290-7297.

Bourguignon LYW, Iida N, Sobrin L, Bourguignon GJ (1994) Identification of an $\mathrm{IP}_{3}$ receptor in endothelial cells. J Cell Physiol 159:29-34.

Brozoski TJ, Brown RM, Rosvold HE, Goldman PS (1979) Cognitive deficit caused by regional depletion of dopamine in prefrontal cortex of rhesus monkey. Science 205:929-932.

Buschmann MT (1979) Development of lamellar bodies and subsurface cisterns in pyramidal cells and neuroblast of hamster cerebral cortex. Am J Anat 155:175-183.

Carlsson A, Waters N, Holm-Waters S, Tedroff J, Nilsson M, Carlsson ML (2001) Interactions between monoamines, glutamate, and GABA in schizophrenia: new evidence. Annu Rev Pharmacol Toxicol 41:237-260.

Castner SA, Williams GV, Goldman-Rakic PS (2000) Reversal of antipsychotic-induced working memory deficits by short-term dopamine D1 receptor stimulation. Science 287:2020-2022.

Centonze D, Grande C, Usiello A, Gubellini P, Erbs E, Martin AB, Pisani A, Tognazzi N, Bernardi G, Moratalla R, Borrelli E, Calabresi P (2003) Receptor subtypes involved in the presynaptic and postsynaptic actions of dopamine on striatal interneurons. J Neurosci 23:6245-6254.

Ciliax BJ, Nash N, Heilman C, Sunahara R, Hartney A, Tiberi M, Rye DB, Caron MG, Niznik HB, Levey AI (2000) Dopamine $\mathrm{D}_{5}$ receptor immunolocalization in rat and monkey brain. Synapse 37:125-145.

Colonnier M (1981) The electron-microscopic analysis of the neuronal organization of the cerebral cortex. In: The organization of the cerebral cortex (Schmitt FO, Worden F, Adelman G, Dennis SG, eds), pp 125-152. Cambridge, MA: MIT.

Delmas P, Brown DA (2002) Junctional signaling microdomains: bridging the gap between the neuronal cell surface and $\mathrm{Ca}^{2+}$ stores. Neuron 36:787-790.

Delmas P, Wanaverbecq N, Abogadie FC, Mistry M, Brown DA (2002) Signaling microdomains define the specificity of receptor-mediated $\mathrm{InsP}_{3}$ pathways in neurons. Neuron 34:209-220.

Dismukes RK (1977) New look at the aminergic nervous system. Nature 269:557-558.

Fagni L, Chavis P, Ango F, Bockaert J (2000) Complex interactions between mGluRs, intracellular $\mathrm{Ca}^{2+}$ stores and ion channels in neurons. Trends Neurosci 23:80-88.

Friedman E, Jin L-Q, Cai G-P, Hollon TR, Drago J, Sibley DR, Wang H-Y (1997) $\mathrm{D}_{1}$-like dopaminergic activation of phosphoinositide hydrolysis is independent of $D_{1 A}$ dopamine receptors: evidence from $D_{1 A}$ knockout mice. Mol Pharmacol 51:6-11.

Gao W-J, Goldman-Rakic PS (2003) Selective modulation of excitatory and inhibitory microcircuits by dopamine. Proc Natl Acad Sci USA 100:2836-2841.

Goldman-Rakic PS (1987) Circuitry of primate prefrontal cortex and regulation of behavior by representational memory. In: Handbook of physiology. The nervous system, Vol 5 (Plum F, Mountcastle V, eds) pp 373417. Bethesda, MD: American Physiological Society.

Goldman-Rakic PS (2002) The "psychic cell" of Ramon y Cajal. Prog Brain Res 136:427-434.

Goldman-Rakic PS, Bergson C, Mrzljak L, Williams GV (1997) Dopamine receptors and cognitive function in nonhuman primates. In: The dopamine receptors (Neve KA, Neve RL, eds), pp 499-522. Totowa, NJ: Humana.

Goldman-Rakic PS, Muly III EC, Williams GV (2000) $D_{1}$ receptors in prefrontal cells and circuits. Brain Res Brain Res Rev 31:295-301.

Gonon F, Burie JB, Jaber M, Benoit-Marand M, Dumartin B, Bloch B (2000) Geometry and kinetics of dopaminergic transmission in the rat striatum and in mice lacking the dopamine transporter. Prog Brain Res 125:291-302.

Henkart M, Landis DMD, Reese TS (1976) Similarity of junctions between 
plasma membranes and endoplasmic reticulum in muscle and neurons. J Cell Biol 70:338-347.

Heydorn A, Søndergaard BP, Hadrup N, Holst B, Renfrew Haft C, Schwartz TW (2004) Distinct in vitro interaction pattern of dopamine receptor subtypes with adaptor proteins involved in post-endocytotic receptor targeting. FEBS Lett 556:276-280.

Jiang Q-X, Thrower EC, Chester DW, Ehrlich BE, Sigworth FJ (2002) Three-dimensional structure of the type 1 inositol 1,4,5-trisphosphate receptor at $24 \AA$ resolution. EMBO J 21:3575-3581.

Johenning FW, Ehrlich BE (2002) Signaling microdomains: InsP $_{3}$ receptor localization takes on new meaning. Neuron 34:173-178.

Kanaseki T, Ikeuchi Y, Tashiro Y (1998) Rough surfaced smooth endoplasmic reticulum in rat and mouse cerebellar Purkinje cells visualized by quick-freezing techniques. Cell Struct Funct 23:373-387.

Khan ZU, Gutiérrez A, Martín R, Penafiel A, Rivera A, de la Calle A (2000) Dopamine D5 receptors of rat and human brain. Neuroscience 100:689-699.

Khan ZU, Koulen P, Rubinstein M, Grandy DK, Goldman-Rakic PS (2001) An astroglia-linked dopamine D2-receptor action in prefrontal cortex. Proc Natl Acad Sci USA 98:1964-1969.

Levey AI, Hersch SM, Rye DB, Sunahara RK, Niznik HB, Kitt CA, Price DL, Maggio R, Brann MR, Ciliax BJ (1993) Localization of $D_{1}$ and $D_{2}$ dopamine receptors in brain with subtype-specific antibodies. Proc Natl Acad Sci USA 90:8861-8865.

Lewis DA, Melchitzky DS, Sesack SR, Whitehead RE, Auh S, Sampson A (2001) Dopamine transporter immunoreactivity in monkey cerebral cortex: regional, laminar, and ultrastructural localization. J Comp Neurol 432:119-136

Lezcano N, Bergson C (2002) D1/D5 dopamine receptors stimulate intracellular calcium release in primary cultures of neocortical and hippocampal neurons. J Neurophysiol 87:2167-2175.

Lidow MS (2003) Calcium signaling dysfunction in schizophrenia: a unifying approach. Brain Res Brain Res Rev 43:70-84.

Lidow MS, Elsworth JD, Goldman-Rakic PS (1997) Down-regulation of the D1 and D5 dopamine receptors in the primate prefrontal cortex by chronic treatment with antipsychotic drugs. J Pharmacol Exp Ther 281:597-603.

Lidow WS, Williams GV, Goldman-Rakic PS (1998) The cerebral cortex: a case for a common site of action of antipsychotics. Trends Pharmacol Sci 19:136-140.

Mahan LC, Burch RM, Monsma FJ, Sibley DR (1990) Expression of striatal $\mathrm{D}_{1}$ dopamine receptors coupled to inositol phosphate production and $\mathrm{Ca}^{2+}$ mobilization in Xenopus oocytes. Proc Natl Acad Sci USA $87: 2196-2200$.

Meldolesi J (2001) Rapidly exchanging $\mathrm{Ca}^{2+}$ stores in neurons: molecular, structural and functional properties. Prog Neurobiol 65:309-338.

Missale C, Nash SR, Robinson SW, Jaber M, Caron MG (1998) Dopamine receptors: from structure to function. Physiol Rev 78:189-225.

Muly III EC, Szigeti K, Goldman-Rakic PS (1998) $\mathrm{D}_{1}$ receptor in interneurons of macaque prefrontal cortex: distribution and subcellular localization. J Neurosci 18:10553-10565.

Novikoff AB (1980) DAB cytochemistry: artifact problems in its current uses. J Histochem Cytochem 28:1036-1038.

Palay SL, Sotelo C, Peters A, Orkand PM (1968) The axon hillock and the initial segment. J Cell Biol 38:193-201.

Park MK, Petersen OH, Tepikin AV (2000) The endoplasmic reticulum as one continuous $\mathrm{Ca}^{2+}$ pool: visualization of rapid $\mathrm{Ca}^{2+}$ movements and equilibration. EMBO J 19:5729-5739.

Peters A, Kara DA (1985a) The neuronal composition of area 17 of rat visual cortex. I. The pyramidal cells. J Comp Neurol 234:218-241.

Peters A, Kara DA (1985b) The neuronal composition of area 17 of rat visual cortex. II. The nonpyramidal cells. J Comp Neurol 234:242-263.

Peters A, Palay SL, Webster HF (1991) The fine structure of the nervous system: neurons and their supporting cells. New York: Oxford UP.

Pickel VM (2000) Extrasynaptic distribution of monoamine transporters and receptors. Prog Brain Res 125:267-276.

Pinton P, Pozzan T, Rizzuto R (1998) The Golgi apparatus is an inositol 1,4,5-trisphosphate-sensitive $\mathrm{Ca}^{2+}$ store, with functional properties distinct from those of the endoplasmic reticulum. ЕMBO J 17:5298-5308.

Rivera A, Alberti I, Martín AB, Narváez JA, de la Calle A, Moratalla R (2002)
Molecular phenotype of rat striatal neurons expressing the dopamine $\mathrm{D}_{5}$ receptor subtype. Eur J Neurosci 16:2049-2058.

Rizzuto R, Bastianutto C, Brini M, Murgia M, Pozzan T (1994) Mitochondrial $\mathrm{Ca}^{2+}$ homeostasis in intact cells. J Cell Biol 126:1183-1194.

Rizzuto R, Pinton P, Carrington W, Fay FS, Fogarty KE, Lifshitz LM, Tuft RA, Pozzan T (1998) Close contacts with the endoplasmic reticulum as determinants of mitochondrial $\mathrm{Ca}^{2+}$ responses. Science 280:1763-1766.

Rosenbluth J (1962) Subsurface cisterns and their relationship to the plasma membrane. J Cell Biol 13:405-421.

Sawaguchi T, Goldman-Rakic PS (1994) The role of D1-dopamine receptor in working memory: local injections of dopamine antagonists into the prefrontal cortex of rhesus monkeys performing an oculomotor delayedresponse task. J Neurophysiol 71:515-528.

Sesack SR, Snyder CL, Lewis DA (1995) Axon terminals immunolabeled for dopamine or tyrosine hydroxylase synapse on GABA-immunoreactive dendrites in rat and monkey cortex. J Comp Neurol 363:264-280.

Sharp AH, McPherson PS, Dawson TM, Aoki C, Campbell KP, Snyder SH (1993) Differential immunocytochemical localization of inositol 1,4,5trisphosphate- and ryanodine-sensitive $\mathrm{Ca}^{2+}$ release channels in rat brain. J Neurosci 13:3051-3063.

Smiley JF, Goldman-Rakic PS (1993) Heterogeneous targets of dopamine synapses in monkey prefrontal cortex demonstrated by serial section electron microscopy: a laminar analysis using the silver-enhanced diaminobenzidine (SEDS) immunolabeling technique. Cereb Cortex 3:223-238.

Smiley JF, Levey AI, Ciliax BJ, Goldman-Rakic PS (1994) $\mathrm{D}_{1}$ dopamine receptor immunoreactivity in human and monkey cerebral cortex: predominant and extrasynaptic localization in dendritic spines. Proc Natl Acad Sci USA 91:5720-5724.

Sumner BE (1975) A quantitative study of subsurface cisterns and their relationships in normal and axotomized hypoglossal neurons. Exp Brain Res 22:175-183.

Sunahara RK, Guan HC, O’Dowd BF, Seeman P, Laurier LG, Ng G, George SR, Torchia J, Van Tol HH, Niznik HB (1991) Cloning of the gene for a human dopamine $D_{5}$ receptor with higher affinity for dopamine than $D_{1}$. Nature 350:614-619.

Syková E (2001) Glial diffusion barriers during aging and pathological states. Prog Brain Res 132:339-363.

Tiberi M, Caron MG (1994) High agonist-independent activity is a distinguishing feature of the dopamine D1B receptor subtype. J Biol Chem 269:27925-27931.

Undie AS, Friedman E (1990) Stimulation of a dopamine D1 receptor enhances inositol phosphates formation in rat brain. J Pharmacol Exp Ther 253:987-992.

Vickery RG, von Zastrow M (1999) Distinct dynamin-dependent and -independent mechanisms target structurally homologous dopamine receptors to different endocytic membranes. J Cell Biol 144:31-43.

Wang H, Pickel VM (2002) Dopamine D2 receptors are present in prefrontal cortical afferents and their targets in patches of the rat caudateputamen nucleus. J Comp Neurol 442:392-404.

Wang H-J, Guay G, Pogan L, Sauvé R, Nabi IR (2000) Calcium regulates the association between mitochondria and a smooth subdomain of the endoplasmic reticulum. J Cell Biol 150:1489-1497.

Wang S, Liu J, Li L, Wice BM (2004) Individual subtypes of enteroendocrine cells in the mouse small intestine exhibit unique patterns of inositol 1,4,5trisphosphate receptor expression. J Histochem Cytochem 52:53-63.

Weinberger DR, Egan MF, Bertolino A, Callicott JH, Mattay VS, Lipska BK, Berman KF, Goldberg TE (2001) Prefrontal neurons and the genetics of schizophrenia. Biol Psychiatry 50:825-844.

Williams GV, Goldman-Rakic PS (1995) Modulation of memory fields by dopamine $\mathrm{D}_{1}$ receptors in prefrontal cortex. Nature 376:572-575.

Yi H, Leunissen JLM, Shi G-M, Gutekunst C-A, Hersch SM (2001) A novel procedure for pre-embedding double immunogold-silver labeling at the ultrastructural level. J Histochem Cytochem 49:279-283.

Yung KKL, Bolam JP, Smith AD, Hersch SM, Ciliax BJ, Levey AI (1995) Immunocytochemical localization of $\mathrm{D}_{1}$ and $\mathrm{D}_{2}$ dopamine receptors in the basal ganglia of the rat: light and electron microscopy. Neuroscience 65:709-730.

Zoli M, Jansson A, Syková E, Agnati LF, Fuxe K (1999) Volume transmission in the CNS and its relevance for neuropsychopharmacology. Trends Pharmacol Sci 20:142-150. 